\title{
ESFOLIAÇÃo E HIDRATAÇÃo DA CAULINITA APÓS INTERCALAÇÃo COM URÉIA.
}

\section{José E. Gardolinski, Fernando Wypych*}

Departamento de Química, Universidade Federal do Paraná, CP 19081, 81531-990 Curitiba - PR

Maurício P. Cantão

Laboratório Central de Pesquisas e Desenvolvimento, Convênio COPEL/UFPR, CP 19067, 81531-970 Curitiba - PR

EXFOLIATION AND HYDRATION OF KAOLINITE AFTER INTERCALATION WITH UREA. Wellordered Georgia kaolinite (Kga-1b) obtained from the source Clay Repository of the Clay Minerals Society (USA) was intercalated with urea using grinding procedures. To achieve complete intercalation $20 \%$ of urea (in weight) was used, producing $\mathrm{Al}_{2} \mathrm{Si}_{2} \mathrm{O}_{5}(\mathrm{OH})_{4}\left(\mathrm{~N}_{2} \mathrm{H}_{4} \mathrm{CO}\right)_{0,86}$ with an interplanar basal spacing of $1,08 \mathrm{~nm}$. After washing with water under ultrasound stirring at $363 \mathrm{~K}$, urea was completely removed and kaolinite was partially exfoliated. After drying under air, the material was converted to hydrated kaolinite with the composition $\mathrm{Al}_{2} \mathrm{Si}_{2} \mathrm{O}_{5}(\mathrm{OH})_{4}\left(\mathrm{H}_{2} \mathrm{O}\right)_{0,64}$ and an interplanar basal spacing of $0,84 \mathrm{~nm}$. In this compound, water molecules positioned between the layers of the silicate can be removed after calcination at $573 \mathrm{~K}$, regenerating structurally disordered kaolinite.

Keywords: kaolinite; aluminosilicate; layered materials.

\section{INTRODUÇÃO}

Processos de intercalação de moléculas orgânicas e inorgânicas nos espaçamentos interlamelares da caulinita são conhecidos há alguns anos ${ }^{1-8}$. Somente recentemente houve um novo interesse nesses tipo de compostos principalmente pela possibilidade de utilização desses materiais para a obtenção de nanocompósitos com potenciais aplicações industriais ${ }^{9-11}$.

A caulinita ao contrário de muitas outras matrizes lamelares apresentam um lacuna de van der Waals com um ambiente químico assimétrico o que pode gerar quiralidade em uma molécula intercalada. Esse fato se deve à características estruturais da caulinita, na qual um lado da lamela é constituído por uma estrutura do tipo da gibsita (variedade polimórfica do $\mathrm{Al}(\mathrm{OH})_{3}$ ), com átomos de alumínio coordenados octaedricamente a oxigênio e grupamentos hidroxila. O outro lado da lamela é constituído por uma estrutura do tipo sílica onde átomos de silício são coordenados tetraedricamente por átomos de oxigênio. Desta forma um lado da lamela contendo alumínio é recoberta com grupamentos hidroxila e o outro, é recoberto com átomos de oxigênio (Figura 1).

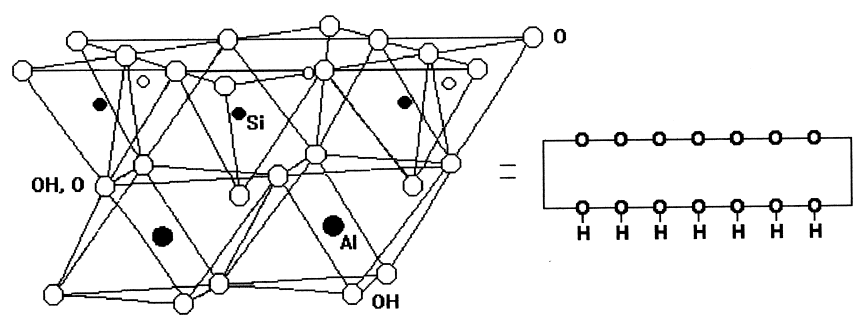

Figura 1. Estrutura da caulinita.

Como as lamelas são ligadas umas as outras através de ligações de hidrogênio, envolvendo os grupamentos Al-OH e $\mathrm{Si}-\mathrm{O}$, existe uma dificuldade em promover processos de intercalação na caulinita. Normalmente moléculas polares são intercaladas as quais são estabilizadas através de interações dipolares, ligações de hidrogênio e forças de van der Waals. Em função da importância desses sistemas, esforços têm se concentrado na caracterização e consequentemente localização dessas moléculas intercaladas ${ }^{12-31}$, além da intercalação de algumas moléculas específicas que possam ser substituídas por outras, não diretamente intercaláveis ${ }^{32-36}$ (método do deslocamento). Uma das maneiras desenvolvidas recentemente, envolve o uso da caulinita hidratada que pode ser preparada tratando-se a caulinita organofuncionalizada, com álcoois ou água ${ }^{37-40}$.

Outras metodologias envolvem a esfoliação parcial da caulinita através dos processos de intercalação com moléculas orgânicas $^{41}$ e inorgânicas ${ }^{42,43}$, porém nesse caso, os compostos intermediários não foram completamente caracterizados.

Um dos intermediários obtidos através da lavagem (com metanol ou etanol) da caulinita intercalada ${ }^{37,38,44}$ é um composto com distância interplanar basal em torno de $1 \mathrm{~nm}$. Como este composto somente existe quando em meio aquoso, a sua caracterização é bastante difícil. Após secagem ao ar, este se converte na caulinita hidratada com distância interplanar basal de cerca de $0,84 \mathrm{~nm}$. Uma das explicações possíveis é que as moléculas de água são co-intercaladas com álcool e que este é eliminado durante o processo de secagem, reduzindo desta forma o espaçamento interplanar basal ${ }^{44}$.

Para contribuir nessa área, o presente trabalho descreve o processo de intercalação da uréia na caulinita através de um simples processo de moagem. Lavando-se o material resultante com água em um banho de ultra-som à $363 \mathrm{~K}$, obtém-se duas fases ou seja, fase esfoliada em meio aquoso (ou pastoso durante a medida de difração de raios-X) seguido de caulinita hidratada, obtida através de secagem ao ar. A caulinita hidratada pode ser novamente intercalada com uréia ou outras moléculas não diretamente intercaláveis ou revertida à caulinita após secagem à $573 \mathrm{~K}$. O processo de esfoliação pode ser interessante do ponto de vista industrial já que a caulinita esfoliada apresenta uma maior plasticidade do que a caulinita na forma cristalina, característica importante na confecção de porcelanas ${ }^{43}$. A matriz utilizada para a intercalação é uma caulinita branca de alta cristalinidade fornecida pelo repositório da Sociedade Americana de Minerais Argilosos (Kga-1b).

\section{PARTE EXPERIMENTAL}

Cerca de $10 \mathrm{~g}$ de caulinita Kga-1b sem purificação prévia foram intimamente misturados com uréia $(20 \%$ e $30 \%$ em mas- 
sa) e moídos à seco num moinho vibratório de ágata (FritshAnalysette 3) por 360 minutos.

$\mathrm{Na}$ tentativa de esfoliar a caulinita, cerca de $0,5 \mathrm{~g}$ da amostra foram adicionados em cerca de $200 \mathrm{~cm}^{3}$ de água destilada e submetido a um tratamento num banho de ultra-som à $363 \mathrm{~K}$ por 25 minutos. Em seguida a amostra foi centrifugada à 4500rpm por 3 minutos e lavada repetidamente com água destilada e analisada ainda úmida e após secagem ao ar. A caulinita hidratada obtida após secagem ao ar foi novamente moída com uréia da mesma forma como descrito para a caulinita pura.

Para as medidas de difratometria de raios-X, filmes orientados foram obtidos sobre porta-amostras de vidro neutro (utilizando-se pó de silício como padrão de calibração interno). As medidas foram realizadas em um difratômetro Rigaku, pelo modo reflexão (radiação $\mathrm{Co}_{\mathrm{K} \alpha}=0,17902 \mathrm{~nm}, 40 \mathrm{kV}$ e $20 \mathrm{~mA}$, filtro de $\mathrm{Ni}$, velocidade de varredura de $1,67 \times 10^{-2} \mathrm{~s}^{-1}$ ).

As curvas simultâneas de termogravimetria (TG) e calorimetria diferencial de varredura (DSC) foram realizadas em um equipamento Netzsch (modelo STA409 Série EP). Os experimentos foram realizados em atmosfera de ar estático, utilizando-se cadinhos de alumina de $0,065 \mathrm{~cm}^{3}$ e cadinhos de alumina vazio como referência. Cerca de $15 \mathrm{mg}$ de amostra foram analisados com uma velocidade de varredura de $1,336 \times 10^{-}$ ${ }^{10} \mathrm{~s}^{-1}$ na faixa de 303 a $1273 \mathrm{~K}$ utilizando-se uma curva de calibração obtida nas mesmas condições, com os cadinhos vazios, a qual foi subtraída das curvas experimentais.

Os espectros na região do infravermelho foram obtidos em um espectrofotômetro com rede de diodos BOMEM MICHELSON série MB100. Para isso o material foi moído com $\mathrm{KBr}$ seco e analisados pelo modo transmissão, na faixa de 400 a $4000 \mathrm{~cm}^{-1}$, com resolução de $2 \mathrm{~cm}^{-1}$ e acumulação de cerca de 100 espectros.

As medidas de microscopia eletrônica de varredura foram realizadas em um microscópio Philips XL 30. As amostras foram suspensas em água e uma gota da suspensão foi alojada em porta-amostras de alumínio. Após um processo de evaporação do solvente por cerca de 1 dia ao ar estas foram recobertas com uma fina camada de ouro (aproximadamente 20nm) pôr meio de pulverização catódica.

\section{RESULTADOS E DISCUSSÃO}

O difratograma de raios- $\mathrm{X}$ do material resultante da síntese da caulinita com uréia, na proporção de $20 \%$ em massa (Figura 2-b) demonstrou que praticamente toda a caulinita foi intercalada, gerando um composto com distância interplanar basal de $1,076 \mathrm{~nm}$, com uma expansão de $0,36 \mathrm{~nm}$ em relação à caulinita pura $(\mathrm{d}=0,716 \mathrm{~nm})^{42}$. No caso da intercalação com $30 \%$ de uréia (Figura 2-c), observou-se a intercalação de praticamente toda a caulinita porém na presença de um excesso de uréia, caracterizada através de uma reflexão intensa na região de $2 \theta=26^{\circ}$ (Figura 2-a). Nos compostos de intercalação, observa-se que a segunda reflexão basal da caulinita pura $(2 \theta=28,9)$ coincide com a terceira reflexão basal do composto intercalado com uréia o que poderia a priori indicar um composto que não sofreu reação com a uréia, porém esse não é o caso como evidenciado a seguir.

Observa-se que após lavagem da amostra intercalada com $20 \%$ de uréia (o mesmo ocorre com a amostra intercalada com $30 \%$ ), esta é totalmente eliminada dos espaçamentos interplanares. Enquanto a amostra se encontra úmida (Figura 3-b) poucos são os planos difratores demonstrando que esta se encontra praticamente amorfa ou esfoliada. Duas pequenas reflexões com espaçamentos interplanares basais em torno de $2,01 \mathrm{~nm}$ e $0,84 \mathrm{~nm}$ foram identificadas além da caulinita pura em $0,72 \mathrm{~nm}$. A primeira pode ser atribuída à uma fase hidratada intermediária e a segunda à fase hidratada estável.

Após o processo de secagem ao ar (Figura 3-a), observouse a caulinita hidratada, possuindo uma reflexão larga com espaçamento interplanar de $0,84 \mathrm{~nm}^{39,40,44}$, além de uma pequena concentração da caulinita original.

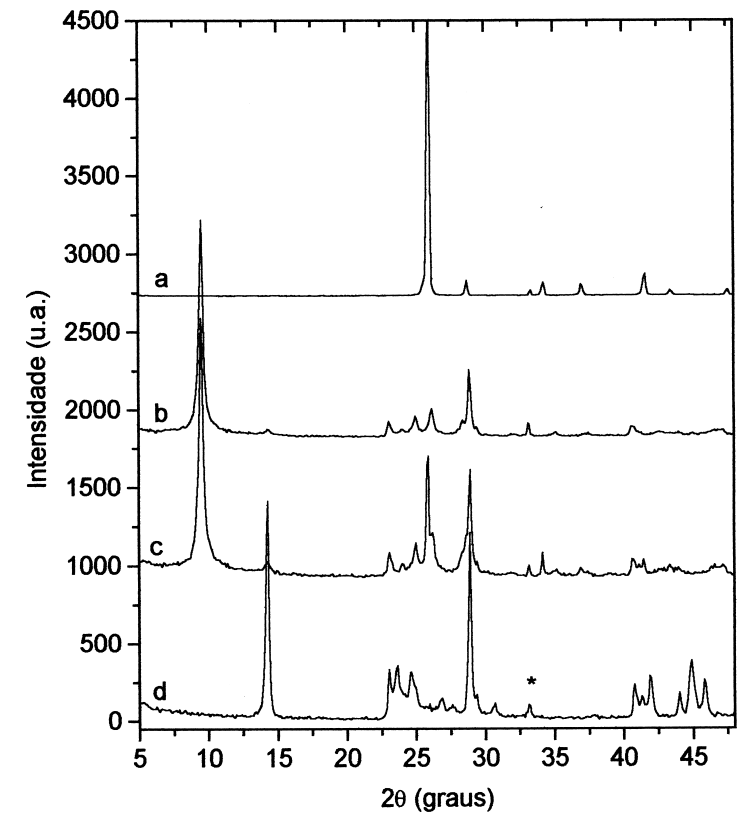

Figura 2. Difratogramas de raios-X da uréia pura (a), caulinita intercalada com uréia na proporção de $20 \%$ (b), $30 \%$ (c) e caulinita pura (d).

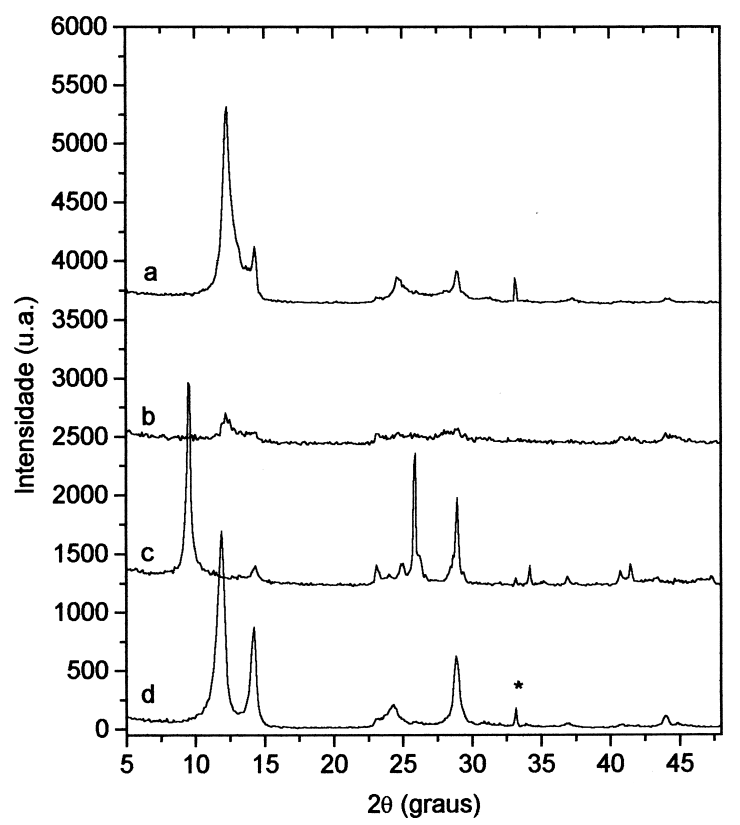

Figura 3. Difratogramas de raios- $X$ da amostra intercalada com $20 \%$ de uréia após lavagem à $90^{\circ} \mathrm{C}$ em um banho de ultra-som e secagem ao ar (a), ainda úmida (b), após moagem do produto seco ao ar (caulinita hidratada) com uréia à $30 \%$ como descrito para a caulinita pura (c) e caulinita hidratada obtida através da lavagem (com metanol) da caulinita intercalada com dimetilsulfóxido $(d)$.

Após moagem da caulinita hidratada seca, com $30 \%$ de uréia, é restabelecida a fase original intercalada com uréia possuindo excesso de uréia (Figura 3-c), demonstrando que a caulinita hidratada se comporta quimicamente de forma semelhante à caulinita pura. Espera-se entretanto que possuindo um maior espaçamento interplanar basal, a água desempenhe um papel importante no rompimento das ligações de hidrogênio, sendo desta forma mais adequada para a intercalação de moléculas não diretamente intercaláveis na caulinita pura. 


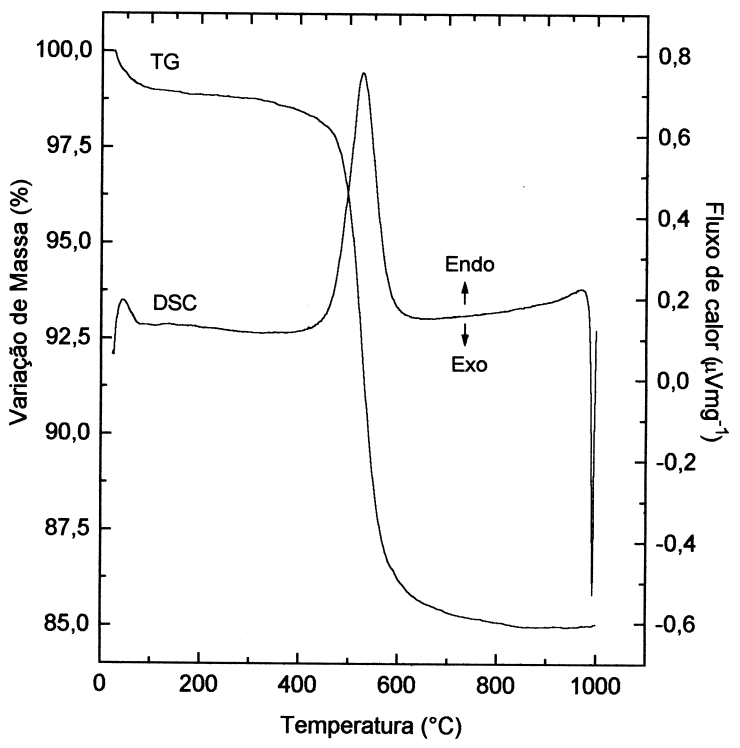

(a)

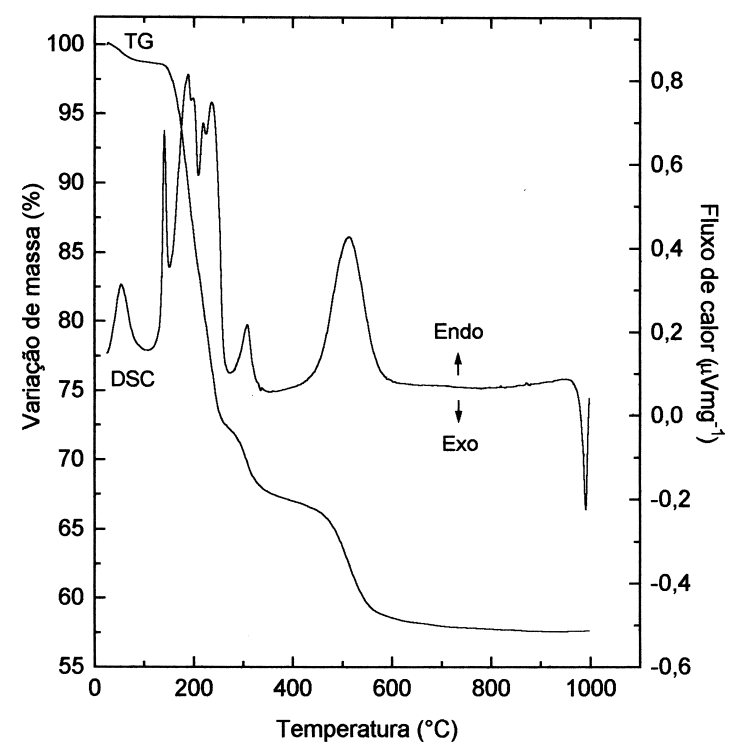

(c)

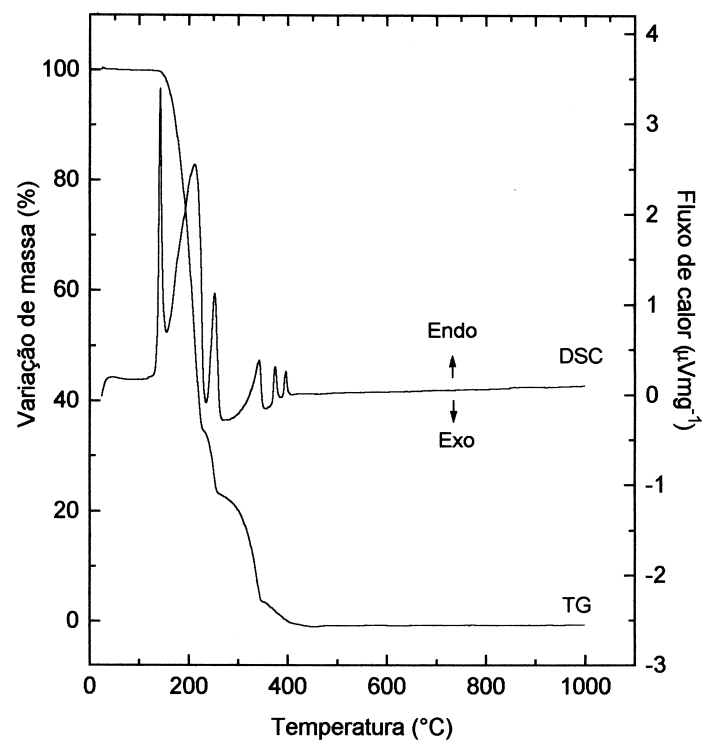

(b)

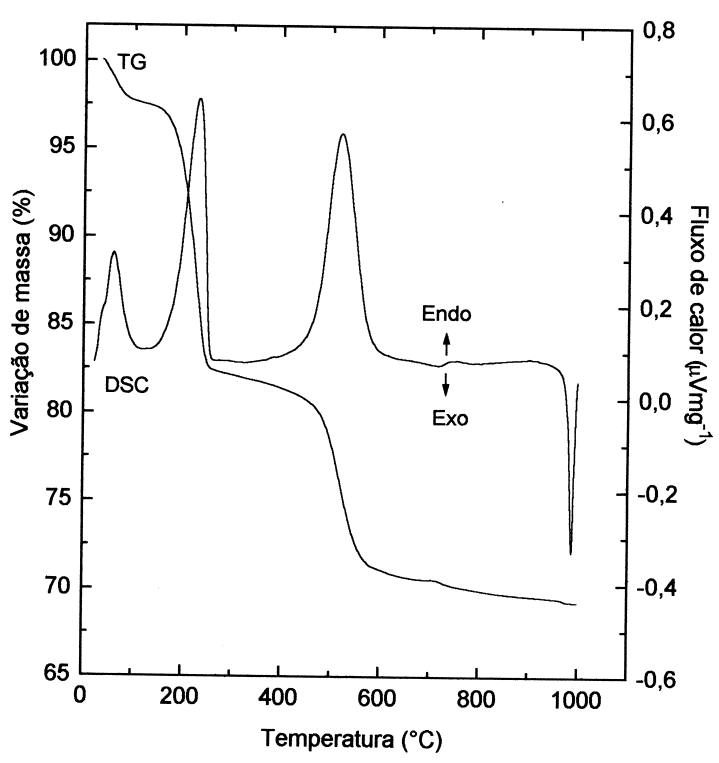

(d)

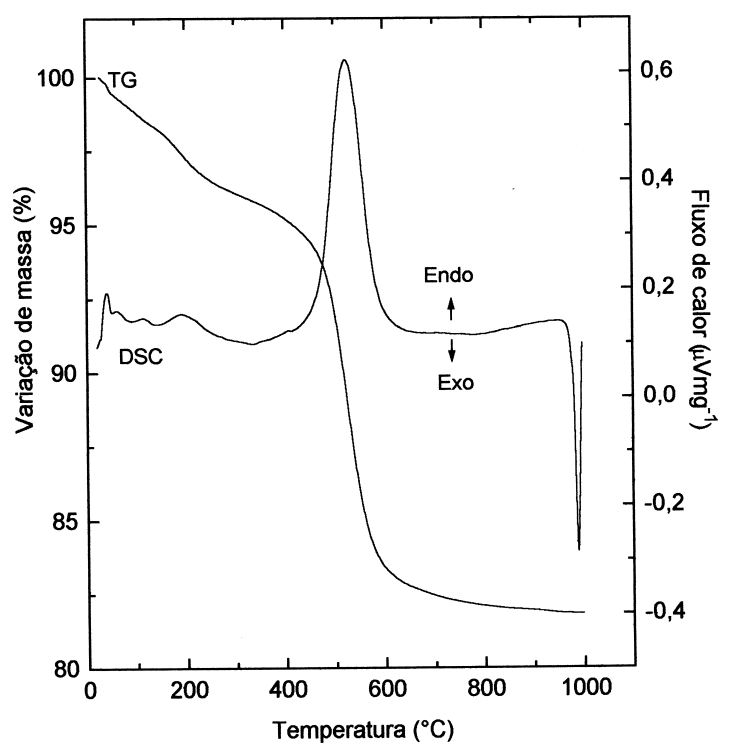

(e)

Figura 4. Curvas de TG/DSC da caulinita pura (a), uréia pura (b), caulinita intercalada com uréia na proporção de $30 \%$ (c) e 20\% (d) e caulinita hidratada (e). 
A caulinita pura (Figura 4-a) apresenta na curva termogravimétrica uma perda de massa relativa à umidade de $1,05 \%$ até $473 \mathrm{~K}$, seguido de um processo de desidroxilação da matriz (pico endotérmico no DSC em 800K) e a cristalização dos óxidos obtidos (pico exotérmico no DSC em 1260K). A perda de massa na curva de TG até $1273 \mathrm{~K}$ em relação da amostra seca é de $14,1 \%$, que é muito próximo do valor esperado de $13,96 \%$ para a composição proposta para a caulinita $\left(\mathrm{Al}_{2} \mathrm{Si}_{2} \mathrm{O}_{5}(\mathrm{OH})_{4}\right)$ e formação de óxidos no final do tratamento térmico ou seja: $\mathrm{Al}_{2} \mathrm{O}_{3}$ e $\mathrm{SiO}_{2}$.

A uréia pura (Figura 4-b) apresenta um perfil de decomposição ao ar bastante complexo iniciando-se com uma fusão associada a um pico endotérmico em $415 \mathrm{~K}$ observado no DSC. Em seguida observa-se uma banda larga endotérmica centrada em 486K seguida de picos endotérmicos em 525, 616, 647 e 669K. Nessa velocidade de varredura foram observados no mínimo 4 passos de decomposição até a completa eliminação da amostra, que ocorre a partir da temperatura de $693 \mathrm{~K}$.

O processo de decomposição da amostra intercalada com uréia na proporção de 30\% (Figura 4-c) apresenta um perfil típico de uma mistura de uréia pura e caulinita intercalada com uréia. $\mathrm{Na}$ curva de TG até 393K observou-se a eliminação da umidade de amostra $(1,36 \%)$ associada a um pico endotérmico em $327 \mathrm{~K}$, observado na curva de DSC. Em seguida observa-se na curva de DSC a fusão do excesso de uréia em 414K e um complexo processo que envolve a decomposição da uréia residual e destruição do composto de intercalação (picos endotérmicos em 462, $472,492,509$ e $581 \mathrm{~K}$ ). A desidroxilação da matriz ocorreu em uma temperatura ligeiramente inferior $(786 \mathrm{~K})$ do que na matriz original $(800 \mathrm{~K})$ demonstrando que o processo de intercalação produz uma desagregação dos cristais o que facilita o processo de desidroxilação. O pico exotérmico relativo à cristalização dos óxidos foi observado em $1264 \mathrm{~K}$ na curva de DSC.

As curvas de TG/DSC da amostra intercalada na proporção de $20 \%$ (Figura 4-d) apresentam um perfil bastante simplificado em relação à proporção de $30 \%$. Nesse caso observa-se na curva de DSC um pico endotérmico em $332 \mathrm{~K}$ associado à desidratação da amostra (até $393 \mathrm{~K}$ perda de massa de 2,48\% observada na curva de TG) seguido de um passo de eliminação da matéria orgânica (pico endotérmico em 504K na curva de DSC e perda de massa de $15,87 \%$ entre $393 \mathrm{~K}$ e $653 \mathrm{~K}$ na curva de TG). A desidroxilação da matriz ocorre em $790 \mathrm{~K}$

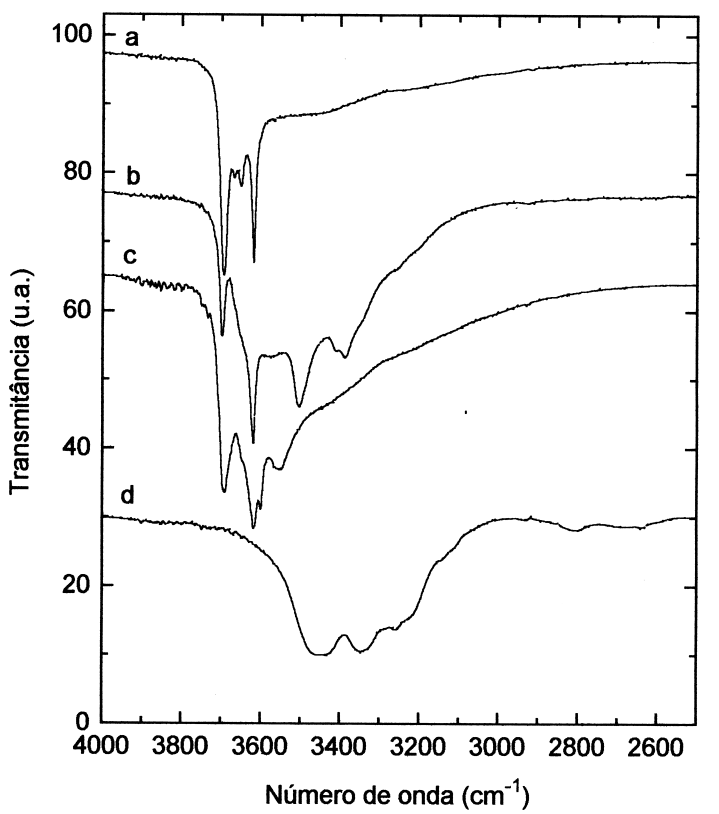

(perda de massa de $12,37 \%$ entre $643 \mathrm{~K}$ e $1273 \mathrm{~K}$ ) além do pico exotérmico em $1261 \mathrm{~K}$. Uma característica interessante nesse sistema está associada com a eliminação de toda a matéria orgânica da amostra sem destruição da matriz além da simplificação do processo de decomposição da uréia que ocorre em somente uma etapa. Observa-se também a ausência do pico de fusão da uréia na curva de DSC, demonstrando que a fase intercalada com $20 \%$ não apresenta uréia não intercalada assim como evidenciado por difratometria de raios-X. Outro fato interessante é a estabilização da decomposição da uréia após o processo de intercalação que ocorre em $504 \mathrm{~K}$, processo que ocorre em $486 \mathrm{~K}$ na uréia pura. A estequiometria gerada a partir dos dados obtidos, $\mathrm{Al}_{2} \mathrm{Si}_{2} \mathrm{O}_{5}(\mathrm{OH})_{4}\left(\mathrm{~N}_{2} \mathrm{H}_{4} \mathrm{CO}\right)_{0,84}$ é bastante próxima da estequiometria prevista a partir da mistura dos reagentes ou seja, $\mathrm{Al}_{2} \mathrm{Si}_{2} \mathrm{O}_{5}(\mathrm{OH})_{4}\left(\mathrm{~N}_{2} \mathrm{H}_{4} \mathrm{CO}\right)_{0,86}$. Quando considerou-se a pureza da amostra (98\%) em função do pequeno pico de caulinita ainda observado, o erro provocado é desprezível em relação à estequiometria.

A fase hidratada (Figura 4-e) apresenta um perfil de decomposição bastante diferenciado. O processo de eliminação de umidade entre a temperatura ambiente e $373 \mathrm{~K}$ na curva de TG $(1,03 \%)$ ocorre acompanhado de dois picos endotérmicos na curva de DSC, centrados em 313 e $332 \mathrm{~K}$. O processo de eliminação da água intercalada entre 373 e $643 \mathrm{~K}(3,27 \%)$ ocorre acompanhado de dois picos endotérmicos de baixa intensidade centrados em 386 e 465K, na curva de DSC. Baseado nesses dados a estequiometria poderá ser obtida $\left(\mathrm{Al}_{2} \mathrm{Si}_{2} \mathrm{O}_{5}(\mathrm{OH})_{4}\left(\mathrm{H}_{2} \mathrm{O}\right)_{0,64}\right)$, sendo desta forma idêntica à fase obtida através da lavagem (com água) da caulinita intercalada com etileno glicol ${ }^{40}$ e fase obtida através da lavagem (com metanol) da caulinita intercalada com dimetilsulfóxido ${ }^{44}$. Entre a temperatura de $643 \mathrm{~K}$ e $1273 \mathrm{~K}$ é observada uma perda de massa de $13,72 \%$ na curva de TG à qual está associada a um pico endotérmico da desidroxilação em $797 \mathrm{~K}$ e um pico exotérmico em $1262 \mathrm{~K}$, característico, observados na curva de DSC. O teor de resíduos total foi de $82,8 \%$, próximo do valor esperado de $83,2 \%$ para a estequiometria proposta.

Como as moléculas orgânicas das fases descritas são eliminadas antes do início do processo de decomposição da caulinita, aquecendo-se até uma temperatura determinada, a caulinita pode ser recuperada, embora sofrendo perda de cristalinidade como conseqüência do processo de intercalação.

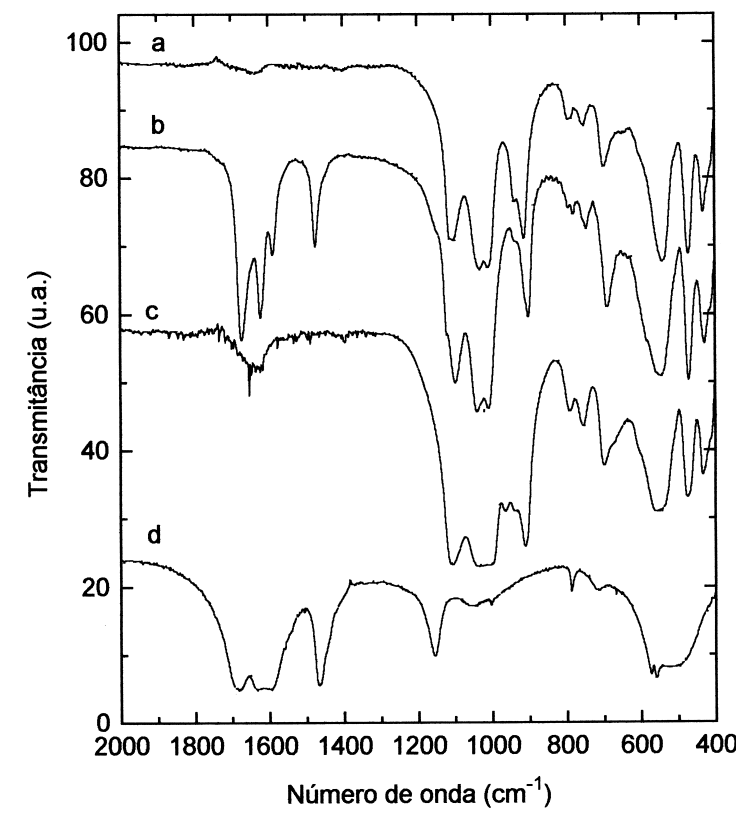

Figura 5. Medidas de FTIR da caulinita pura (a), caulinita intercalada com uréia na proporção de 20\% (b), fase hidratada (c) e uréia pura $(d)$. 
A
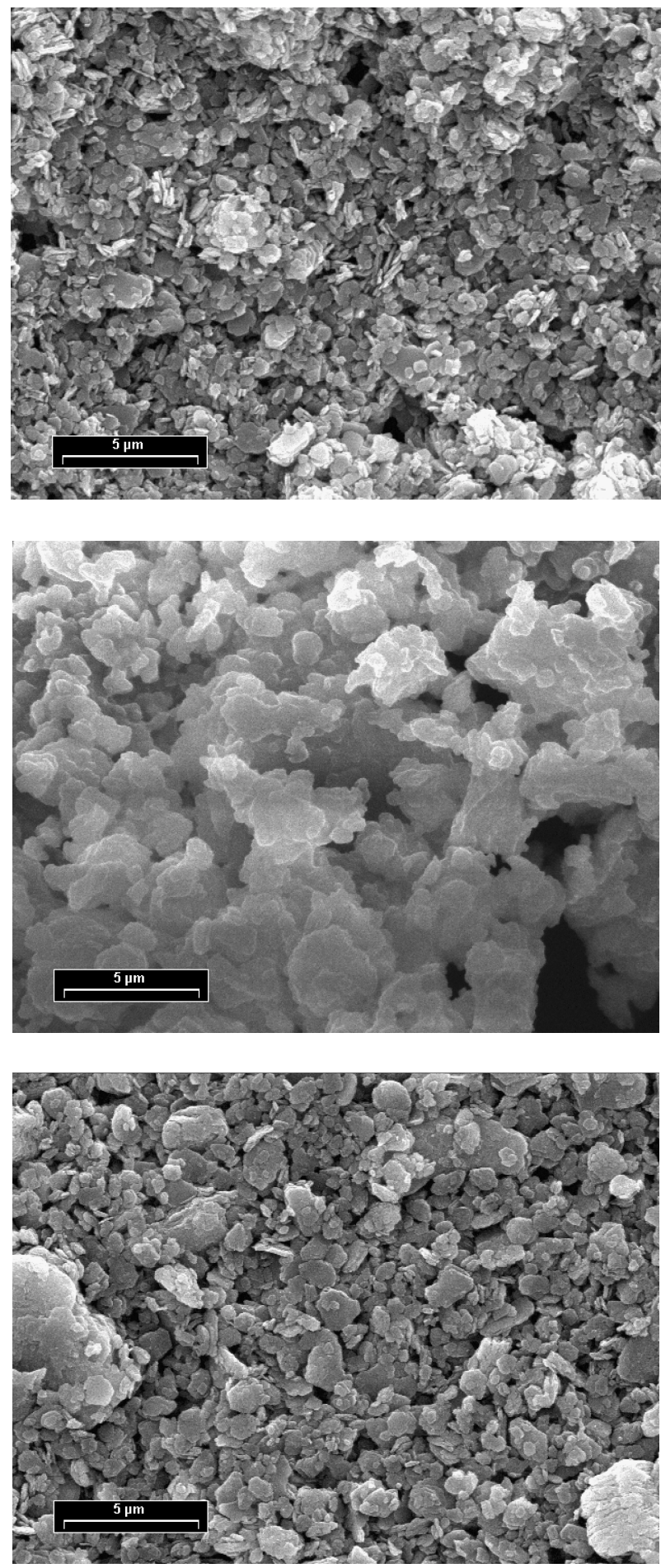

B

(a)

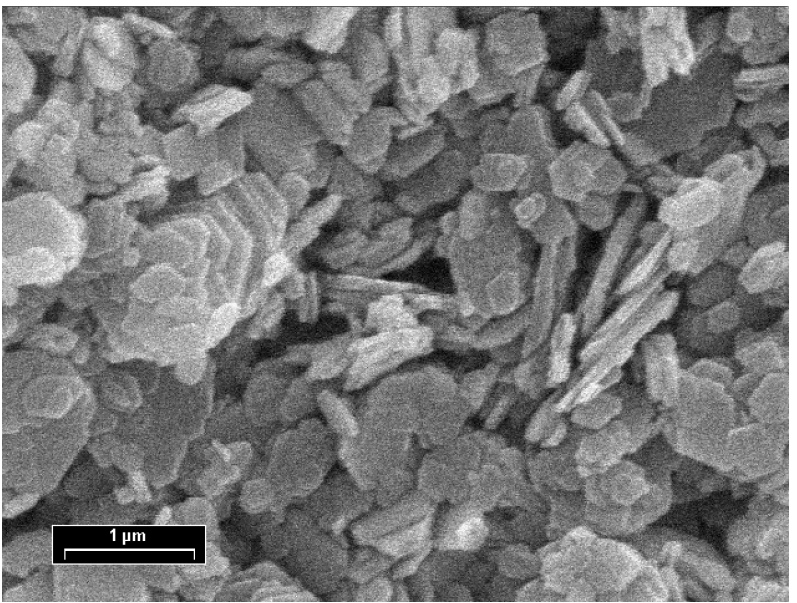

(b)

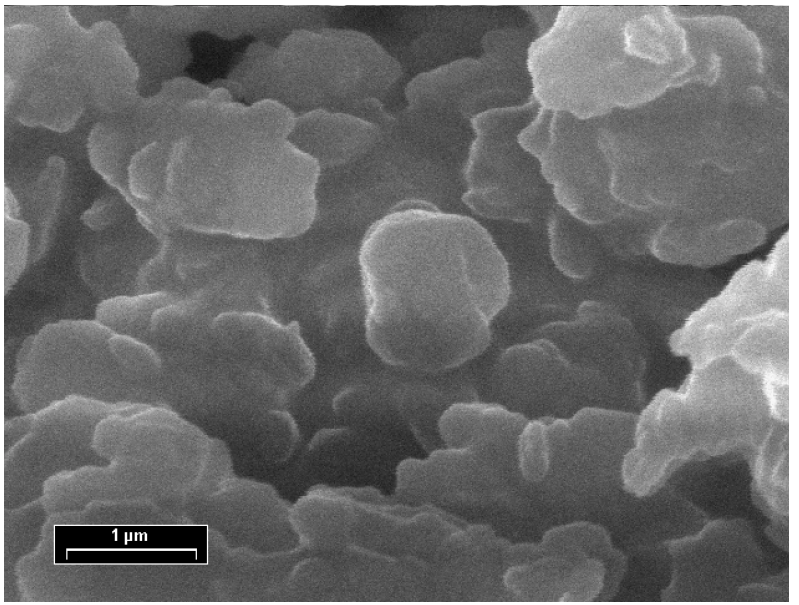

(c)

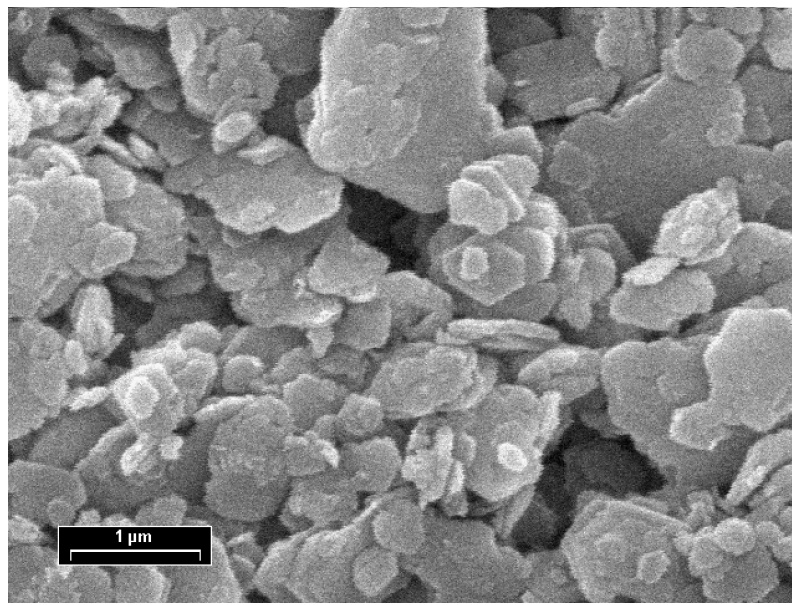

Figura 6. Micrografias obtidas através de microscopia eletrônica de varredura da caulinita pura (a), caulinita intercalada com uréia na proporção de $20 \%$ (b) e fase esfoliada após secagem ao ar (c). Barras de $5 \mu m(A)$ e $1 \mu m(B)$.

Observa-se no espectro de FTIR da caulinita pura (Figura 5 -a) bandas relativas às hidroxilas externas observadas em 3694,3669 e $3651 \mathrm{~cm}^{-1}$ e hidroxilas internas em $3619 \mathrm{~cm}^{-1} 45,46$.

Após o processo de intercalação (Figura 5-b), a região relativa às hidroxilas entre 3200 e $3800 \mathrm{~cm}^{-1}$ é bastante afetada, principalmente em relação ao desaparecimento das bandas rela- tivas às hidroxilas externas em 3651 e $3669 \mathrm{~cm}^{-1}$ e diminuição da intensidade da banda em $3698 \mathrm{~cm}^{-1}$, ligeiramente deslocada para maiores números de onda em relação à caulinita pura ${ }^{42}$. Observou-se ainda a manutenção da banda relativa às hidroxilas internas em $3619 \mathrm{~cm}^{-1}$ e surgimento de novas bandas em 3504, 3411 e $3388 \mathrm{~cm}^{-1}$. Essas novas bandas são associadas à ligação 
da molécula de uréia às hidroxilas externas da lamela da caulinita. Essa é uma evidência a mais do processo de interação da uréia com os grupamentos hidroxila interlamelares. As bandas observadas em 1467, 1617 e $1686 \mathrm{~cm}^{-1}$ observadas na uréia pura são deslocadas para $1475,1590,1622$ e $1673 \mathrm{~cm}^{-1}$ no composto intercalado. A banda atribuída aos grupamentos hidroxila superficiais é perturbada sendo deslocado de $914 \mathrm{~cm}^{-1}$ na caulinita para $903 \mathrm{~cm}^{-1}$ na amostra intercalada com uréia, as demais bandas não sofrem alterações significativas.

$\mathrm{Na}$ fase hidratada (Figura 5-c) observou-se um perfil característico com a manutenção da banda relativa a hidroxilas internas $\left(3618 \mathrm{~cm}^{-1}\right)$, um ombro em 3649 e um pico em $3692 \mathrm{~cm}^{-1}$, relativos às hidroxilas externas além do surgimento de novas bandas em 3600 e $3556 \mathrm{~cm}^{-1}$. O pequeno pico em $1655 \mathrm{~cm}^{-1}$ é atribuído à banda de deformação da molécula de água. A banda atribuída aos grupamentos hidroxila superficiais retorna praticamente a sua posição original ou seja $912 \mathrm{~cm}^{-1}$ porém uma nova banda foi observada em $965 \mathrm{~cm}^{-1}$ o que demonstra a interação entre as moléculas de água intercaladas e hidroxilas externas. Não se pode excluir a possibilidade de que algum produto de decomposição da uréia possa sobrar entre as lamelas ${ }^{42}$, porém após lavagem a quente, a fase final é a caulinita hidratada. Essa fase é idêntica àquela reportada anteriormente ${ }^{40,44}$, como confirmado pôr difratometria de raios-X, análise térmica e FTIR.

A Figura 6 apresenta as micrografias obtidas através de microscopia eletrônica de varredura da caulinita pura (a), caulinita intercalada com uréia na proporção de $20 \%$ (b) e fase esfoliada após secagem ao ar (c). Barras de $5 \mu \mathrm{m}$ (A) e $1 \mu \mathrm{m}$ (B).

Observa-se que a caulinita pura (Figura 6-a) apresenta cristais hexagonais na forma de pilastras e cristais na forma de lamelas. A maioria dos cristais apresenta cantos definidos e ângulos próximos de $120^{\circ}$, característicos da estrutura da caulinita.

Após o processo de intercalação (Figura 6-b) a caulinita se apresenta na forma de cristais arredondados ligados uns aos outros formando uma espécie de matriz, consequiência da presença da uréia intercalada. O processo de moagem e intercalação foi responsável pelo arredondamento dos cantos do cristais e delaminação das pilastras transformando-as em cristais lamelares.

Após o processo de esfoliação, os cristais se apresentam menores, mais finos e livres da matriz como observado na figura 5-b. Os ângulos próximos de $120^{\circ}$, característicos da caulinita original, são novamente observados nos cristais da caulinita esfoliada. Este fato demonstra que provavelmente a uréia intercalada (obviamente presente nas bordas do cristal) é a responsável pelo aparente arredondamento dos cristais, na caulinita intercalada (Figura 6-b).

Alguns cristais são ainda observados na forma de pilastras, provavelmente sendo relativos à caulinita não reagida, presente em todos os difratogramas de raios-X.

Embora a caulinita hidratada não deva ser confundida com a haloisita $^{45-47}$ já que as duas diferem em alguns aspectos, existem algumas coincidências.

A diferença mais marcante está relacionada com o hábito dos cristais, ou seja, caulinita hidratada se apresenta na forma de cristais lamelares enquanto que na haloisita (com duas moléculas de água de hidratação e anidra), são tubulares ${ }^{45,47}$. Apesar desta diferença, haloisita pode apresentar um desenrolamento dos cristais após desidratação ${ }^{47}$, passando à estrutura lamelar.

As estequiometrias entre a haloisita $\left(\mathrm{Al}_{2} \mathrm{Si}_{2} \mathrm{O}_{5}(\mathrm{OH})_{4}\left(\mathrm{H}_{2} \mathrm{O}\right)_{2,0} \mathrm{e}\right.$ caulinita hidratada $\left(\mathrm{Al}_{2} \mathrm{Si}_{2} \mathrm{O}_{5}(\mathrm{OH})_{4}\left(\mathrm{H}_{2} \mathrm{O}\right)_{0,64}\right)$ são muito distintas embora teores variáveis de água possam ser observados durante o processo de desidratação da haloisita à haloisita anidra.

O mesmo acontece com as distâncias interplanares basais que embora muito distintas (haloisita $-1,01 \mathrm{~nm}$ e caulinita hidratada $-0,84 \mathrm{~nm})^{45-47}$, distâncias intermediárias entre os dois extremos possam ser identificadas pôr difração de raios-X "in-situ”, durante o processo de desidratação da haloisita. A caulinita hidratada e a haloisita regeneram a caulinita (ou haloisita anidra tubular) após desidratação total ${ }^{47}$.
Os picos observados pôr FTIR na região entre 3200 e $3800 \mathrm{~cm}^{-1}$, diferem somente nas intensidade, embora essa característica possa ser explicada pelo variável teor de água interlamelar (haloisita com duas moléculas de água de hidratação - 3695 , 3620,3602 e $3550 \mathrm{~cm}^{-1}$ e caulinita hidratada - 3692, 3649, 3619, 3600 e $\left.3556 \mathrm{~cm}^{-1}\right)$. Na região entre 2000 e $400 \mathrm{~cm}^{-1}$, embora as diferenças sejam muito sutis, os espectros se aproximam mais aos da caulinita do que da haloisita ${ }^{46}$

Apesar de que não existe nenhum citação na literatura relativo à identificação de caulinita hidratada na natureza, é bastante provável de que essa fase possa ser identificada, principalmente em depósitos mistos haloisita/caulinita.

Experimentos realizados na esfoliação total da caulinita através do uso de surfactantes, preparação de nanocompósitos além do uso da caulinita hidratada para a intercalação de moléculas precursoras de polímeros estão sendo realizados e serão motivos de publicações futuras ${ }^{48,49}$.

\section{CONCLUSÕES}

Moendo-se a uréia com a caulinita obtém um composto com uma distância interplanar basal de 1,076nm, característico da intercalação da uréia entre as lamelas da matriz. Excedendo-se o limite de $20 \%$ de uréia (em massa), um excesso de uréia foi observado no material final, caracterizado pôr todas as técnicas utilizadas.

Dados de FTIR demonstram claramente o efeito da intercalação da uréia e água, entre as lamelas da caulinita, através de perturbações de algumas vibrações específicas, principalmente àquelas ligadas aos grupamentos hidroxila externos.

Lavando-se a caulinita intercalada com uréia à quente com água obtém-se uma caulinita desordenada (parcialmente esfoliada) a qual após secagem se ordena na forma de caulinita hidratada, contaminada em pequenas proporções com caulinita original. A fase hidratada (incluindo a impureza de caulinita) poderá ser novamente intercalada com uréia após o processo de moagem, de forma idêntica ao reportado para a caulinita pura. A caulinita hidratada poderá ser desidratada à caulinita pura com desordem estrutural após tratamento térmico ou ser utilizada como intermediário para a intercalação de moléculas não diretamente intercaláveis.

\section{REFERÊNCIAS}

1. Frost, R. L.; Lack, D. A.; Paroz, G. N.; Tran, T. H. T.; Clays Clay Miner. 1999, 47, 297.

2. Frost, R. L.; Kristof, J.; Paroz, G. N.; Kloprogge, J. T.; Phys. Chem. Miner. 1999, 26, 257.

3. Olejnik, S.; Posner, A. M.; Quirk, J. P.; Clay Miner. 1970, 8, 421.

4. Sugahara, Y.; Kitano, S.; Satokawa, S.; Kuroda, K.; Kato, C.; Bull. Chem. Soc. Jpn. 1986, 59, 2607.

5. Gardolinski,J. E.; Ramos, L. P.; Pinto de Souza, G.; Wypych, F.; J. Colloid Interface Sci. 2000, 221, 284.

6. Wypych, F.; Gardolinski, J. E.; Peralta-Zamora, P.; J. Colloid Interface Sci. 1999, 211, 137.

7. Frost, R. L.; Kristof, J.; Horvath, E.; Kloprogge, J. T.; J. Colloid Interface Sci. 1999, 214, 109.

8. Wada, N.; Raythatha, R.; Minomura, S.; Solid State Commun. 1987, 63, 783.

9. Sugahara, Y.; Satokawa, S.; Kuroda, K.; Kato, C.; Clays Clay Miner. 1990, 38, 137.

10. Tunney, J. J.; Detellier, C.; Chem. Mat. 1996, 8, 927.

11. Gardolinski, J. E.; Carrera, L. C. M.; Cantão, M. P.; Wypych, F.; J. Mater. Sci. 2000, 35, 3113.

12. Gábor, M.; Tóth, M.; Kristóf, J.; Komáromi-Hiller, G.; Clays Clay Miner. 1995, 43, 223.

13. Horte, C. H.; Becker, C.; Kranz, G.; Schiller, E.; Wiegmann, J.; J. Thermal Anal. 1988, 33, 401. 
14. Thompson, J. G.; Cuff, C.; Clays Clay Miner. 1985, 33, 490.

15. Thompson, J. G.; Uwins, P. J. R.; Whittaker, A. K.; Mackinnon, I. D. R.; Clays Clay Miner. 1992, 40, 369.

16. Jackson, M. L.; Abdel-Kader, F. H.; Clays Clay Miner. 1978, 26, 81 .

17. Frost, R. L.; Kloprogge, J. T.; Tran, T. H. T.; Kristof, J.; Am. Miner. 1998, 83, 1182.

18. Tombácz, E.; Szekeres, M.; Baranyi, L.; Michéli, E.; Colloids Surf., A 1998, 141, 379.

19. Frost, R. L.; Vassallo, A. M.; Clays Clay Miner. 1996, 44, 635.

20. Akiba, E.; Hayakawa, H.; Hayashi, S.; Miyawaki, R.; Tomura, S.; Shibasaki, Y.; Izumi, F.; Asano, H.; Kamiyama, T.; Clays Clay Miner. 1997, 45, 781.

21. Shoval, S.; Yariv, S.; Michaelian, K. H.; Lapides, I.; Boudeuille, M.; Panczer, G.; J. Colloid Interface Sci. 1999, 212, 523 .

22. Frost, R. L.; Clays Clay Miner. 1998, 46, 280.

23. Hayashi, S.; Clays Clay Miner. 1977, 45, 724.

24. Frost, R. L.; Tran, T. H.; Kristof, J.; Clay Miner. 1997, 32,587

25. Xie, X.; Hayashi, S.; J. Phys. Chem. B 1999, 103, 5949.

26. Xie, X.; Hayashi, S.; J. Phys. Chem. B 1999, 103, 5956.

27. Frost, R. L.; Forsling, W.; Holmgren, A.; Kloprogge, J. T.; Kristof, J.; J. Raman Spect. 1998, 29, 1065.

28. Robie, R. A.; Hemingway, B. S.; Clays Clay Miner. 1991, 39, 362.

29. Johnston, C. T.; Sposito, G.; Bocian, D. F.; Birge, R. R.; J. Phys. Chem. 1984, 88, 5959.

30. Olejnik S.; Aylmore, L. A. G.; Posner, A. M.; Quirk, J. P.; J. Phys. Chem. 1968, 72, 241.

31. Kristóf, J.; Tóth, M.; Gábor, M.; Szabó, P.; Frost, R. L.; J. Thermal Anal. 1997, 49, 1441.
32. Sugahara, Y.; Satokawa, S.; Yoshioka, K.; Kuroda, K.; Kato, C.; Clays Clay Miner. 1989, 37, 143.

33. Komori, Y.; Sugahara, Y.; Kuroda, K.; J. Mater. Res. 1998, 13, 930.

34. Komori, Y.; Sugahara, Y.; Kuroda, K.; Chem. Mater. 1999, 11, 3 .

35. Komori, Y.; Sugahara, Y.; Kuroda, K.; Appl. Clay Sci. 1999, $15,241$.

36. Kuroda, K.; Hiraguri, K.; Komori, Y.; Sugahara, Y.; Mouri, H.; Uesu, Y.; Chem. Commun. 1999, 2253.

37. Raythatha, R.; Lipsicas, M.; Clays Clay Miner. 1985, 33, 333.

38. Costanzo, P. M.; Clemency, C. V.; Giese Jr., R. F.; Clays Clay Miner. 1980, 28, 155.

39. Tunney, J. J.; Detellier, C.; Clays Clay Miner. 1994, $42,552$.

40. Tunney, J. J.; Detellier, C.; Clays Clay Miner. 1994, 42, 473.

41. Lahav, N.; Clays Clay Miner. 1990, 38, 219.

42. Tsunematsu, K.; Tateyama, H.; J. Am. Ceram. Soc. 1999, $82,1589$.

43. Maxwell, C. B.; Malla, P. B.; Am. Ceram. Soc. Bull. 1999, 57.

44. Gardolinski, J. E.; Dissertação de Mestrado, UFPR, Curitiba, PR, 2001.

45. Gomes, C. F.; Argilas. O que são e para que servem, Fundação Calouste Gulbenkian, Lisboa, 1986.

46. Russel J. D.; Fraser, A. R.; In Clay Mineralogy: Spectroscopic and Chemical Determinative Methods; Wilson, M. J. Ed.; Chapman and Hall; London, 1994.

47. Santos, P. S.; Ciência e Tecnologia de Argilas, Editora Edgard Blücher Ltda; vol 1, 1989, São Paulo.

48. Gardolinski, J. E.; Cantão, M. P.; Wypych, F.; resultados não publicados.

49. Gardolinski, J. E.; Cantão, M. P.; Wypych, F.; resultados não publicados. 